\title{
Experimental study of heat transfer from in-line tube bundles to upward foam flow
}

\author{
J. Gylys ${ }^{1}$, I. Gabrielaitiene ${ }^{1}$, T. Zdankus ${ }^{1}$, S. Sinkunas ${ }^{2}$ \\ \& R. Maladauskas ${ }^{2}$ \\ ${ }^{I}$ Energy Technology Institute, Kaunas University of Technology, Lithuania \\ ${ }^{2}$ Department of Thermal and Nuclear Energy, Kaunas University of Technology, \\ Lithuania
}

\begin{abstract}
The heat transfer from the in-line tube bundle to the vertically upward directed laminar aqueous foam flow was investigated by means of experimental set-up, consisting of the foam generator, experimental channel, in-line tube bundle, measurement instrumentation and auxiliary equipment. Two in-line tube bundles with different geometries were used for the experiments. One bundle consisted of three rows with six tubes in each. Spacing between centres of the tubes across the experimental channel was $s_{l}=0.06 \mathrm{~m}$ and spacing along the channel was $s_{2}=0.03 \mathrm{~m}$. The second in-line tube bundle consisted of five vertical rows with six tubes in each. Spacing between centres of the tubes was $s_{1}=s_{2}=0.03 \mathrm{~m}$. All tubes had an external diameter of $0.02 \mathrm{~m}$. Statically stable foam was used for experiments. It was noticed that structure of foam varied while it passed the bundle: bubbles changed their size, liquid drainage from the foam appeared. Dependence of heat transfer intensity on flow velocity, volumetric void fraction of foam and liquid drainage was determined and described by empirical relationships. Moreover, density and the pattern of tubes location were estimated in experiments and the development of the heat transfer computation method.

Keywords: two-phase foam flow, in-line tube bundle, heat transfer, void fraction of foam.
\end{abstract}

\section{Introduction}

Development of heat exchangers with low consumption of primary energy resources and the enhanced heat transfer rates is the aim of this work. This issue 
is addressed by applying an advance heat transfer carrier, such as aqueous foam flow, consisting of gas bubbles separated by a thin liquid film. Foam coolant can be applied on heated surfaces only when bubbles of it don't collapses and retain their structure during transportation to heat transfer place and process of heat transfer. One type of aqueous foam - statically stable foam keeps initial dimensions and structure of bubbles within broad limits of time and velocity of motion; therefore it is suitable for heat transfer purpose [1]. To apply two phase foam flow in practice and to utilize effectively this type of coolant deep investigations of foam and heat exchanger interaction to be performed and influence of foam, flow and exchanger characteristics to heat transfer intensity are vitally needed. Drainage of liquid from foam [2, 3], diffusive transfer of gas between bubbles [3], division and collapse of foam bubbles [4, 5] take place in foam type heat exchangers. Those phenomena are closely linked between themselves what complicates very much application of analytical methods. Thus an experimental method was selected for our investigations as the most convenient and universal.

Heat transfer from single tube and tube line to statically stable foam flow was investigated in our previous works [6], therefore we have requires experience and necessary equipment. After these works an experimental series with in-line tube bundles in foam flow followed [7, 8]. The effect of tube bundles' geometries is the focus of this work, since bundles (behaving as obstacles in a flow) induce substantial changes of foam structure: bubbles are transformed by collapsing, dividing, appearing news bubbles. This, together with gravity and capillary forces, facilitates the liquid drainage from the foam and affects the thickness of liquid film, composing on the heated surfaces and channel walls. Such effects can significantly increase or decrease heat transfer rates. The results of our investigation are presented in this paper.

\section{Experimental set-up}

Experimental set-up consisted of the following elements [6, 7]: experimental channel, tube bundle, gas and liquid control valves, gas and liquid flow meters, liquid storage reservoir, liquid level control reservoir, air fan, electric current transformer and stabilizer. Cross section of the experimental channel had dimensions $0.14 \times 0.14 \mathrm{~m}^{2}$; height of it was $1.8 \mathrm{~m}$.

Two in-line tube bundles with different spacing between tubes centres across the bundle were used during experimental investigation. A schematic view of the experimental channel with tube bundles is shown in the Fig. 1. The in-line tube bundle No.1 consisted of three vertical rows with six tubes in each. Spacing between centres of the tubes across the experimental channel was $s_{I}=0.06 \mathrm{~m}$ and spacing along the channel was $s_{2}=0.03 \mathrm{~m}$. The in-line tube bundle No. 2 consisted of five vertical rows with six tubes in each. Spacing between centres of the tubes was $s_{1}=s_{2}=0.03 \mathrm{~m}$. External diameter of all the tubes was equal to $0.02 \mathrm{~m}$. An electrically heated tube - calorimeter had an external diameter equal to $0.02 \mathrm{~m}$ also. Endings of the calorimeter were sealed and insulated. During the experiments calorimeter was placed instead of one tube of the bundle. An 
electric current value of heated tube was measured by an ammeter and voltage by a voltmeter. Temperature of the calorimeter surface was measured by eight calibrated thermocouples: six of them were placed around the central part of the tube and two of them were placed in both sides of the tube at a distance of 50 $\mathrm{mm}$ from the central part. Temperature of the foam flow was measured by two calibrated thermocouples: one in front of the bundle and one behind it.
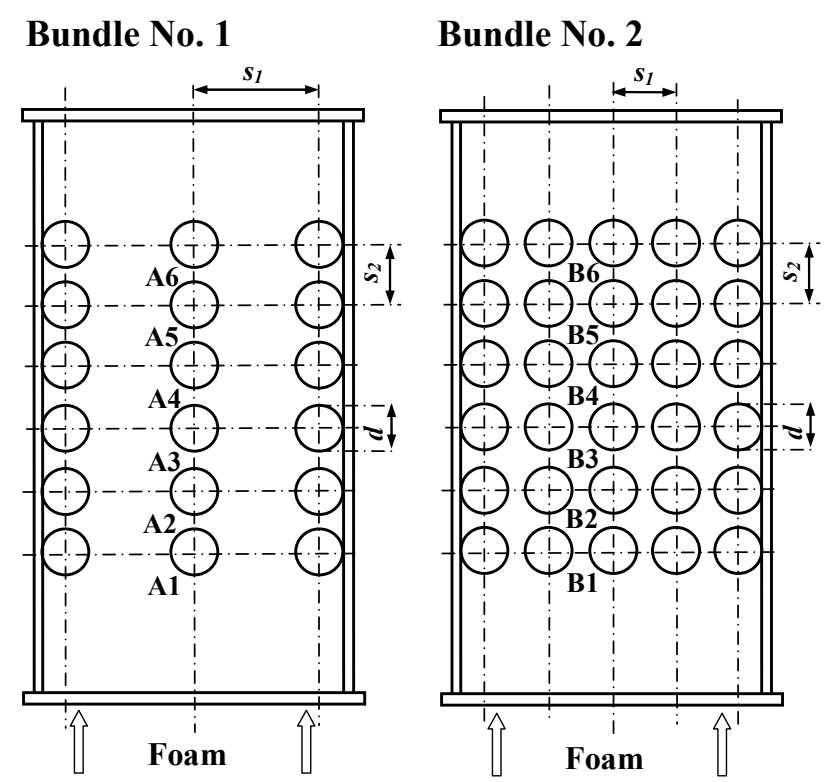

Figure 1: $\quad$ In-line tube bundle No. 1 and No. 2 in upward foam flow.

Statically stable foam flow was used for an experimental investigation. This type of foam was generated from water solution of detergents. Concentration of detergents $(0.5 \%)$ was kept constant. Foam flow was produced by gas and liquid mixing on the riddle, which was installed at the bottom of the experimental channel. Liquid was delivered from the reservoir to the riddle from the upper side; gas was supplied to the riddle from below.

Measurement accuracies for flows, temperatures and heat fluxes were of range correspondingly $1.5 \%, 0.15-0.20 \%$ and $0.6-6.0 \%$.

During the experimental investigation a relationship was obtained between an average heat transfer coefficient $h$ from one side and foam flow volumetric void fraction $\beta$ and gas flow Reynolds number $R e_{g}$ from the other side:

$$
N u_{f}=f\left(\beta, \operatorname{Re}_{g}\right) .
$$

Nusselt number was computed by formula

$$
N u_{f}=\frac{h d}{\lambda_{f}} .
$$


Here $\lambda_{f}$ is the thermal conductivity of the statically stable foam flow, $\mathrm{W} /(\mathrm{m} \cdot \mathrm{K})$, computed by the equation

$$
\lambda_{f}=\beta \lambda_{g}+(1-\beta) \lambda_{l} .
$$

An average heat transfer coefficient we calculated as

$$
h=\frac{q_{w}}{\overline{\Delta T}} .
$$

Gas Reynolds number of foam flow we computed by formula

$$
\operatorname{Re}_{g}=\frac{G_{g} d}{A v_{g}} .
$$

Foam flow volumetric void fraction we expressed by the equation

$$
\beta=\frac{G_{g}}{G_{g}+G_{l}} .
$$

Experiments we performed within limits of Reynolds number diapason for gas $\left(R e_{g}\right)$ : 190-410 (laminar flow regime) and foam volumetric void fraction $(\beta)$ : 0.996-0.998. Gas velocity for foam flow was changed from 0.14 to $0.32 \mathrm{~m} / \mathrm{s}$.

\section{Results}

The process of heat transfer from in-line tube bundle to upward foam flow was investigated experimentally. Tube bundle No.1 (see Fig. 1) was the subject of our research. The influences of foam flow gas $R e_{g}$ numbers and tube position on heat transfer intensity $N u_{f}$ were evaluated for middle-line (A) tubes of tube bundle No.1 (Fig. 2). Heat transfer from the first tube (A1) to foam flow is more intensive than that of the other tubes for the entire interval of $R_{g}$. Heat transfer of the second tube (A2) is lower than that of the third tube (A3). The heat transfer intensity of the third (A3), fourth (A4) and fifth (A5) tubes is almost the same - the difference is less than 5\%. Heat transfer from the fifth (A5) tube to foam flow is slight higher than that of the third (A3) and fourth (A4) tubes. The exception is the last - the sixth (A6) tube. Heat transfer intensity of this tube is lower than that of the first (A1) tube and higher than that of the other tubes. This phenomenon can be explained by the fact that structure of foam flow changes while it passes the tube bundle. Passing the bundle the large bubbles of foam are divided into smaller ones, some of foam bubbles collapse. Therefore the real void fraction and the intensity of the liquid drainage process increases along the tube bundle. So, the heat transfer intensity from the last tubes to foam flow increases.

Average heat transfer intensity from the second (A2) tube to foam flow ( $\beta=$ 0.997 ) is equal to $63 \%$ of the first (A1) tube heat transfer intensity. The same of the third (A3) tube is equal to $81 \%$ of the second (A2) tube heat transfer intensity to foam flow. It is different in comparison with one-phase flow case, where the highest heat transfer intensity is of the third and furthered tubes and the heat transfer intensity of frontal (first) tubes are equal to about $60 \%$ of the third tubes 
heat transfer intensity $[8,9]$. Results showed that the heat transfer intensity from the bundles' third (A3) and further tubes varies insignificantly (except the last tube). It's the same in comparison with one-phase flow case.

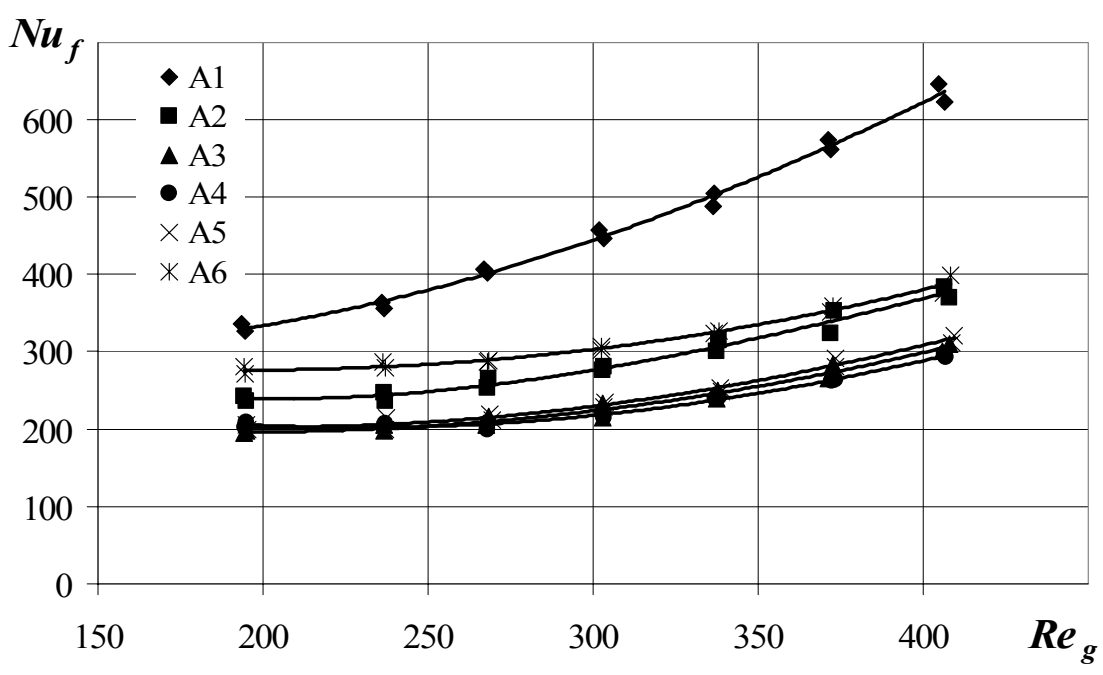

Figure 2: Heat transfer intensity from the tubes of the middle-line (A) to upward foam flow, $\beta=0.997$.

Comparison of heat transfer intensity from both bundles' third tubes (A3 and B3) to upward foam flow is shown in the Fig. 3. Heat transfer from the tube A3 (tube bundle No.1) increased by 1.5 times for $\beta=0.996$, by 1.6 times for $\beta=0.997$, and by 1.4 times for $\beta=0.998$ for upward foam flow, when gas flow Reynolds numbers $R e_{g}$ are changed from 190 to 410 . For the B3 tube (tube bundle No.2), the heat transfer increased by 2.1 times for $\beta=0.996,1.9$ times for $\beta=0.997$, and by 1.8 times for $\beta=0.998$.

Heat transfer intensity of the tube B3 is higher than that of the tube A3 on average by $58 \%$ for $\beta=0.996$ and 0.997 and by $50 \%$ for $\beta=0.998$, for $R e_{g}=190$ 440.

An average heat transfer rate of middle-line tubes was calculated in order to compare the experimental results of in-line tube bundles No.1 and No.2. An average heat transfer intensity of the middle-line tubes (A and $\mathrm{B}$ ) of the in-line bundle No.1 and No.2 to upward foam flow is shown in Fig. 4.

When foam is passing through the obstacle (the tube bundle) flow velocity increases, foam bubbles are intermixed, some bubbles collapsed or divided into smaller bubbles. These processes are more intensive in the case of tube bundle No.2, where five tubes are located across the channel in comparison with three tubes of the bundle No.1. Therefore average heat transfer intensity from the middle-line tubes (B) of the bundle No.2 to foam flow is higher than that of the middle-line tubes (A) of the bundle No.1. 


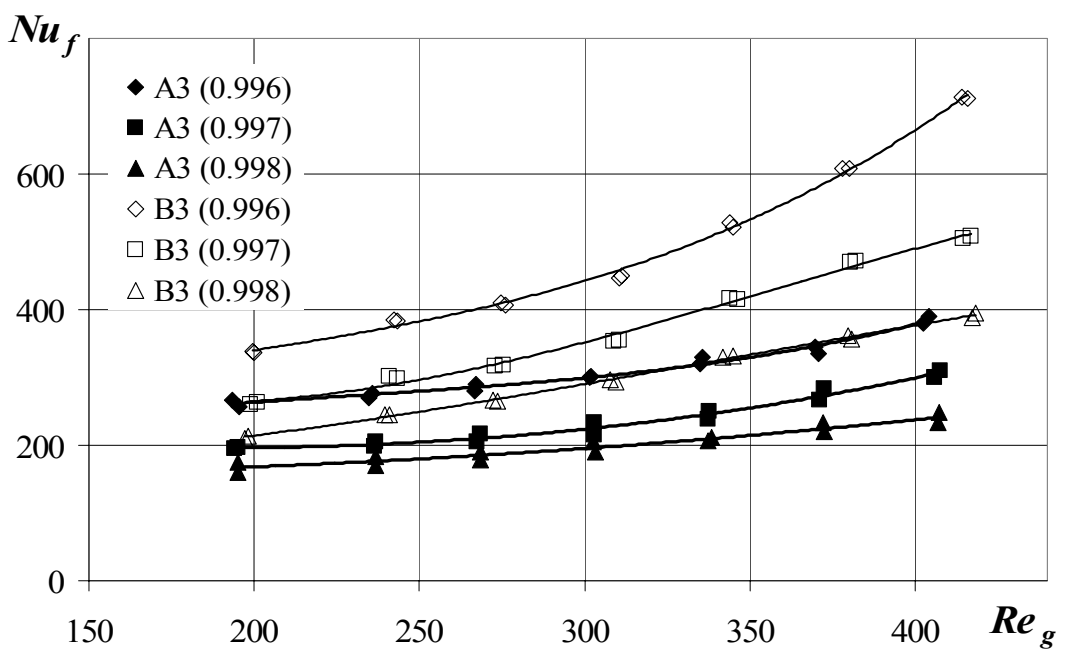

Figure 3: Heat transfer from the tubes A3 and B3 to upward foam flow, $\beta=0.996,0.997$ and 0.998 .

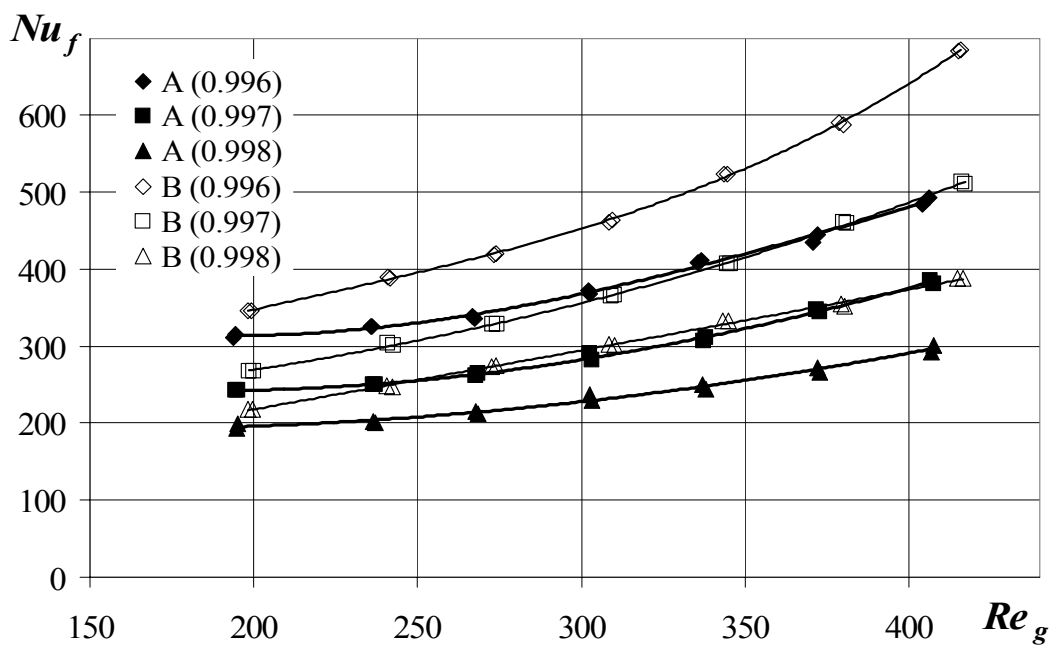

Figure 4: Average heat transfer intensity from the middle-line tubes of the in line bundle No. 1 and No. 2 to upward foam flow: $\beta=0.996,0.997$ and 0.998 .

Changing $R e_{g}$ from 190 to 410, an average heat transfer intensity of the middle-line tubes of the in-line bundle No.1 to upward foam flow increases by 1.6 times for $\beta=0.996$ and 0.997 , and by 1.5 times for $\beta=0.998$; and that for the tubes of the in-line bundle No. 2 is twice for $\beta=0.996$; by 1.9 times for $\beta=0.997$, and by 1.8 times for $\beta=0.998$. 
An average heat transfer intensity from the tubes of the tube bundle No.2 is higher than that of the tubes of the bundle No.1 on average by $27 \%$ for $\beta=0.996-$ 0.998 , to upward foam flow for entire interval of $R e_{g}\left(R e_{g}=190-440\right)$.

Experimental results of investigation of heat transfer from the in-line tube bundles to upward statically stable foam flow were generalized by criterion equation using dependence between Nusselt number $N u_{f}$ and gas Reynolds $R e_{g}$ number. This dependence within the interval $190<R e_{g}<410$ for the in-line tube bundle in upward foam flow with the volumetric void fraction $\beta=0.996,0.997$, and 0.998 can be expressed as follows:

$$
N u_{f}=c \beta^{n} \operatorname{Re}_{g}^{m} .
$$

On average, for the whole middle-line tubes of bundle No.1 $\left(s_{l}=0.06\right.$ and $s_{2}=0.03 \mathrm{~m}$ ) in the upward foam flow $c=7.4, n=-111, m=22.8(1.023-\beta)$.

On average, for the whole middle-line tubes of bundle No.2 $\left(s_{l}=s_{2}=0.03 \mathrm{~m}\right)$ in the upward foam flow $c=5.7, n=340, m=102.1(1.006-\beta)$.

\section{Conclusions}

Heat transfer of two in-line tube bundles with different geometry to vertical laminar upward statically stable foam flow was investigated experimentally.

Heat transfer from the first tubes of the in-line bundle to foam flow moving in upward direction is higher than that of the next tubes, what is different in comparison with one-phase fluid flow case.

Heat transfer intensity from the third and the other (excluding the last) tubes are similar and close to that of one-phase flow case.

An average heat transfer intensity from the tubes of the tube bundle No.2 $\left(s_{I}=s_{2}=0.03 \mathrm{~m}\right)$ is higher than that of the tubes of the bundle No.1 $\left(s_{I}=0.06\right.$ and $s_{2}=0.03 \mathrm{~m}$ ) on average by $27 \%$ for $\beta=0.996-0.998$, to upward foam flow for entire interval of $R e_{g}=190-440$.

Criterion equation (7) may be applied for calculation and design of the statically stable foam heat exchangers with in-line tube bundles.

\section{Nomenclature}

$A$ - cross section area of experimental channel, $\mathrm{m}^{2} ; c, m, n$ - coefficients; $d$ outside diameter of tube, $\mathrm{m} ; G$ - volumetric flow rate, $\mathrm{m}^{3} / \mathrm{s} ; N u-$ Nusselt number; $q$ - heat flux density, $\mathrm{W} / \mathrm{m}^{2} ; R e$ - Reynolds number; $\bar{T}$ - average temperature, $\mathrm{K} ; h$ - average coefficient of heat transfer, $\mathrm{W} /\left(\mathrm{m}^{2} \cdot \mathrm{K}\right) ; \beta-$ volumetric void fraction; $\lambda$ - thermal conductivity, $\mathrm{W} /(\mathrm{m} \cdot \mathrm{K}) ; v$ - kinematic viscosity, $\mathrm{m}^{2} / \mathrm{s}$.

\section{Indexes}

$f$ - foam;

$g$ - gas; 
$l$ - liquid;

$w$ - wall of heated tube.

\section{Acknowledgement}

The authors gratefully acknowledge the financial support of the Lithuanian Science Foundation.

\section{References}

[1] Gylys, J., Hydrodynamics and Heat Transfer Under the Cellular Foam Systems, Technologija: Kaunas, 1998.

[2] Nguyen A. V., Liquid Drainage in Single Plateau Borders of Foam. Journal of Colloid and Interface Science, 249(1), pp. 194-199, 2002.

[3] Tichomirov V., Foams. Theory and Practice of Foam Generation and Destruction, Chimija: Moscow, 1983.

[4] Vilkova N. G. and Kruglyakov P. M., Investigation of foam and emulsion destruction under the great pressure gradients. Advances in Colloid and Interface Science, 108-109, pp. 159-165, 2004.

[5] Garrett P. R, Recent developments in the understanding of foam generation and stability. Chemical Engineering Science, 48(2), pp. 367-392, 1993.

[6] Gylys J., Giedraitis V., Sinkunas S., Zdankus T. and Gylys M., Study of inline tube bundle heat transfer in upward vertical foam flow, Energy: production, distribution and conservation ASME conference, Milan, Italy, pp. 643-650, 2006.

[7] Gylys J., Zdankus T., Sinkunas S., Giedraitis V., Study of In-line Tube Bundle Cooling in Vertical Foam Flow. WSEAS Transactions on Heat and Mass Transfer, Iss. 6, 1, pp. 632-637, 2006.

[8] Zukauskas A., Convectional Heat Transfer in Heat Exchangers, Nauka: Moscow, p. 472, 1982.

[9] Hewitt, G. F., Heat exchanger design handbook 2002, York, Begell House, 2002 . 